
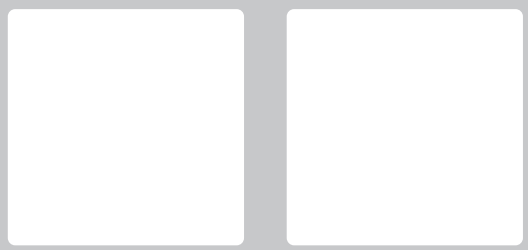

\title{
Os lugares de fala das mulheres acadêmicas no campo do empreendedorismo no Brasil: Um estudo entre os anos de 2005 e 2020
}

\section{Standpoint of academic women in the scientific field of entrepreneurship in Brazil: A study between 2005 and 2020}

O presente trabalho foi realizado com apoio da Coordenação de Aperfeiçoamento de Pessoal de Nível Superior - Brasil (CAPES) - Código de Financiamento 001.

Lara Ferreira Rezende Camargo

Universidade Federal de Goiás

email:larareezende@outlook.com
Josiane Silva de Oliveira

Universidade Federal de Goiás email:josiane.ufg@gmail.com

\section{RESUMO}

O estudo tem como objetivo discutir os lugares de fala das mulheres acadêmicas que pesquisam e publicam no campo do empreendedorismo no Brasil. Para o alcance do objetivo foi utilizada uma abordagem quantitativa através de uma revisão bibliométrica de artigos publicados por mulheres, sendo analisados por meio da estatística descritiva com apoio do software RStudio Cloud. O material empírico coletado possibilitou a identificação de seis lugares das mulheres acadêmicas no campo, sendo eles: lugares no espaço-tempo, lugares nas publicações, lugares nos periódicos, lugares temáticos, lugares organizacionais e lugares geográficos. Os resultados demonstram uma relação direta dos lugares de fala das mulheres pesquisadoras com as dinâmicas estruturais da sociedade, nesse estudo demonstrada pela dinâmica socioeconômica em relação à localização das instituições de ensino superior das quais essas autoras enunciam suas pesquisas.

Palavras-Chave: gênero; lugares de fala; empreendedorismo; Brasil.

\section{ABSTRACT}

This study aims to discuss the standpoints of academic women who research and publish in the field of entrepreneurship in Brazil. To achieve the objective, a quantitative approach was used through a bibliometric review of articles published by women, being analyzed using descriptive statistics with the support of RStudio Cloud software. The empirical material collected enabled the identification of five standpoints of academic women in the field, namely: places in space-time, places in publications, places in journals, thematic places, organizational places and geographical places. The results demonstrate a direct relationship between the places of speech of women researchers with the structural dynamics of society, in this study demonstrated by the socioeconomic dynamics in relation to the location of higher education institutions from which these authors enunciate their research.

Key-words: gender; standpoint; entrepreneurship; Brazil. 


\section{INTRODUCTION}

De uma maneira geral, o conhecimento científico cresceu significativamente nas últimas décadas e, em comparação com outros campos de pesquisa, o do empreendedorismo demonstrou um crescimento significativo em termos de quantidade de publicações e, também, de variedades de temas pesquisados (LANDSTRÖM; HARIRCHI, 2018).

Em pesquisas mais recentes no campo do empreendedorismo nota-se uma predominância de estudos que se baseiam exclusivamente na experiência masculina, reforçando, mesmo que involuntariamente ou não, o empreendedorismo como uma forma de masculinidade (HAMILTON, 2013). Autores destacaram dez temas promissores do empreendedorismo, onde "gênero e correlatos" aparece em $4^{\circ}$ lugar na lista, demonstrando que este é um tema importante para ser abordado dentro do empreendedorismo (LOPES; LIMA, 2019).

Apesar de estudos explorarem explicitamente a experiência empreendedora das mulheres, não demonstram como gênero se articula através e dentro do empreendedorismo (HAMILTON, 2013), continuando centrados em discussões sobre a identificação das singulares características das empreendedoras femininas e também sobre como as empreendedoras atuam frente aos seus empreendimentos (PEÑALOZA; DIÓGENES; SOUSA, 2008) e também nas diferenças entre empreendedores homens e mulheres (HENRY; FOSS; AHL, 2016).

De acordo com Joan Scott (1995), em termos de gramática, o conceito de gênero foi utilizado para classificar fenômenos sociais a partir de elementos que sejam consensuais e não inerentes ao que se está conceituando, permitindo constituir agrupamentos e distinções a partir de categorias de análise. Em termos de produção de agrupamentos nas ciências sociais, o termo gênero se estabeleceu com o objetivo de destacar o caráter social das distinções que eram baseadas no sexo biológico entre seres humanos (SCOTT, 1995).

Ao integrar questões de gênero na produção do conhecimento científico relacionado ao empreendedorismo, deparamo-nos com o silenciamento acadêmico das mulheres enquanto teóricas, mesmo sendo "objetos" de estudos no campo (AISTON; FO,
2021). Reconhecer a voz e o espaço ocupado por essas mulheres é relevante, uma vez que a voz é como uma declaração pública de afirmação da posição de uma pessoa sobre determinado assunto ou também sobre a sua identidade e localização na grade demográfica das diferenças atribuídas socialmente (LUKE, 1994).

Djamila Ribeiro (2017) apresenta um conceito importante relacionado ao reconhecimento dessa voz, o lugar de fala. A autora afirma que as reflexões e trabalhos gerados com base nessa perspectiva foram moldados no seio dos movimentos sociais, sendo possível pensar esse termo por meio de certas referências que começam a questionar quem pode falar.

Sabendo da existência da divisão entre estudos do empreendedorismo e estudos de gênero é necessário fazer uma integração entre esses dois campos e não apenas adicionar gênero aos estudos do empreendedorismo e vice-versa (HOLMQUIST; SUNDIN, 2020), é importante compreender como se constituem e se influenciam mutuamente.

Com a finalidade de discutir aspectos de gênero nos estudos do empreendedorismo, reconhecer a voz das mulheres autoras no campo, bem como quais são os seus lugares de fala, o objetivo da pesquisa foi discutir os lugares de fala das mulheres acadêmicas que pesquisam e publicam no campo do empreendedorismo no Brasil. Para isso, discutimos teoricamente os conceitos de gênero e suas relações com os debates sobre lugar de fala. Do ponto de vista metodológico, realizamos um estudo quantitativo, a partir de uma bibliometria, sendo os artigos coletados no repositório SPELL e os dados analisados por meio da estatística descritiva com suporte do software RStudio Cloud. Os resultados da pesquisa indicam que a localização geográfica, a escolha da temática e o vínculo institucional são elementos centrais para a compreensão dos lugares de fala das mulheres na área do empreendedorismo no Brasil, resultando em seis lugares identificados, sendo estes lugares no espaço-tempo, lugares nas publicações, lugares nos periódicos, lugares temáticos, lugares organizacionais e lugares geográficos.

Este artigo, além dessa seção introdutória, está organizado em: duas seções teóricas, sendo a primeira dedicada a discussão sobre gênero e a segunda sobre lugar de fala; uma seção metodológica, que apresenta como o material empírico da pesquisa foi coletado 
e analisado; duas seções destinadas à discussão e análise dos resultados, sendo a primeira voltada a apresentação dos lugares estruturais e, a segunda, para a apresentação das principais autoras do campo; finalizando com a seção de conclusão e referências.

\section{DISCUTINDO GÊNERO}

O corpo sexuado, durante muito tempo, foi utilizado como base para se compreender a constituição e classificação social dos seres humanos (SCOTT, 1995). Existiam duas possibilidades de classificação de nossa existência: homem e mulher, pois eram categorias dadas biologicamente, nascer biologicamente homem ou mulher significaria reproduzir um conjunto de categorias sociais vinculadas a essa condição (SCOTT, 1995).

De acordo com Joan Scott (1995) por gênero ser vinculado ao sexo, nascer homem ou mulher biologicamente implicaria no exercício de um conjunto de categorias sociais vinculadas a essa classificação, sendo estas masculinas e femininas, respectivamente. A autora acrescenta ainda que o exercício social dessas classificações também implicaria em um conjunto de elementos que deveriam ser incorporados pelos seres humanos.

Scott (1995) destaca a relevância teórica que a categoria gênero começou a ter no século XX. O entendimento da diferença entre gênero e sexo advém desses debates. A definição de gênero, para esta autora, recai em duas bases principais: gênero é considerado como um elemento constitutivo de relações sociais baseadas nas diferenças percebidas entre os sexos; e gênero é uma forma primária que dá significado às relações de poder.

Para desenvolver o argumento de que gênero se constitui a partir das relações sociais com base em diferenças que soam perceptíveis, Scott (1995), elenca quatro elementos de análise. O primeiro é que essas diferenças são pautadas em representações simbólicas contextualizadas. O segundo elemento discutido pela autora se refere aos conceitos normativos que produzem e expressam significados de símbolos e possibilidades metafóricas para compreender as diferenças de gênero e de sexo. $O$ terceiro elemento se refere a necessidade de um debate sobre gênero destacar as concepções políticas e as referências institucionais e de organização social que são produzidas ao se falar sobre gênero. $\mathrm{O}$ quarto elemento se refere a identidade de gênero, para a autora as identidades são substantivamente construídas.

Neste ponto é necessário fazer uma discussão em relação as diferenças existentes entre sexo biológico, identidade de gênero e orientação sexual. $\mathrm{O}$ sexo biológico, para a biologia, se relaciona às células reprodutivas, onde homens possuem os espermatozoides como células reprodutivas e mulheres possuem os óvulos (JESUS, 2012).

Gênero, por sua vez, é uma definição construída socialmente, dessa forma elementos são utilizados para a construção de autodefinições e autopercepções sobre como nos expressamos socialmente, ao se falar em identidade de gênero estamos indo além do que é determinado biologicamente (JESUS, 2012).

A vivência de gênero pode acontecer de duas formas, por meio da correspondência e da discordância com o sexo biológico (JESUS, 2012). Ainda segundo essa autora, quando a vivência de gênero ocorre a partir da sua correspondência com o sexo biológico, considera-se que uma pessoa é cisgênero, por exemplo, uma pessoa nasce biologicamente mulher e se define socialmente como mulher, sendo chamada de mulher cisgênero. Quando essa vivência ocorre através da discordância entre os elementos biológicos e sociais, considera-se que uma pessoa é transgênero, por exemplo, uma pessoa nasce biologicamente homem, mas se define socialmente como mulher, sendo então chamada de mulher transgênero.

Já a orientação sexual trata sobre aspectos relacionados à atração e constituição de relações afetivo-sexuais, sendo uma pessoa denominada heterossexual quando é atraída por alguém do sexo oposto e homossexual quando essa atração ocorre por pessoas do mesmo sexo (JESUS, 2012). Porém essas não são as únicas maneiras de se pensar gênero e sexualidade, pode-se pensar essa relação a partir de múltiplas possibilidades de constituição (REIS; PINHO, 2016).

A segunda base de discussão de gênero proposta por Scott (1995), de que gênero é uma forma primeira de significar relações de poder, defende que, em geral, não se considera gênero de forma explícita para compreender a organização de igualdade e de 
desigualdade em nossa sociedade. Não se pode considerar gênero sem associar outras categorizações sociais articuladas a esse processo de construção. É preciso compreender a complexidade desse conceito. Para isso, avançaremos nossa discussão em relação à construção de gênero vinculado às mulheres, que são tema deste estudo.

Simone de Beauvoir (1970) apresenta a categoria do "Outro" e argumenta que nenhuma coletividade consegue se definir com uma se não colocar imediatamente a "Outra" frente a si, sendo a mulher vista como o "Outro". Por estarem nessa condição de outro, as mulheres nunca tiveram uma relação direta e autônoma com os homens, estes por sua vez ao buscarem a manutenção de suas prerrogativas masculinas criaram um campo de domínio feminino onde a mulher deveria se encerrar nele (BEAUVOIR, 1970).

Entretanto, o que de fato é ser uma mulher? Simone de Beauvoir (1967) argumenta que ninguém nasce mulher, torna-se mulher, ainda mais, nenhum destino biológico, psíquico e econômico irá definir a forma que a fêmea humana assume na sociedade. Nem todo ser humano do sexo feminino é mulher, entretanto, todos aqueles que nascem biologicamente mulher conhecem mais intimamente o mundo feminino do que aqueles que nascem biologicamente homens, visto que elas possuem suas raízes nesse mundo e acabam por aprender imediatamente o que significa pertencer ao sexo feminino (BEAUVOIR, 1970).

Mesmo as contribuições de Beauvoir (1970) sendo relevantes para se discutir gênero, possuem suas limitações. Um conceito que possibilita realizar articulações entre gênero e sociedade, gênero e hierarquia de poder é o conceito de lugar de fala, discutido na próxima seção.

\section{LUGARES DE FALA}

Ribeiro (2017) é uma das autoras responsáveis por popularizar o termo lugar de fala no Brasil. Porém, ainda não há uma epistemologia determinada sobre esse termo e até mesmo a sua origem é imprecisa, sugere-se que este surgiu a partir da tradição de discussão sobre feminist standpoint - diversidade, teoria racial crítica e pensamento decolonial (RIBEIRO, 2017).

Partindo das considerações de Ribeiro (2017) iniciamos a discussão sobre o que é lugar de fala. Vale ressaltar que a autora traz um conceito de discurso baseado na noção foucaultiana. Para Foucault (2008) um discurso pode ser caracterizado por um conjunto de enunciados, apoiados na mesma formação discursiva (a exemplo de gênero, raça ou sexualidade), sendo constituído de um número limitado de enunciados que possibilitam definir um conjunto de condições de existência.

Como exemplo desse conjunto de condições de existência produzidas pelos discursos podemos citar aqueles direcionados ao fato do gênero feminino ser mais frágil, o que acaba por produzir materialidades, como categorias profissionais. Dessa forma, as profissões que exigem o que entendem como sendo de mais cuidado, devido a sua fragilidade, acabam sendo associadas às mulheres. Os atravessamentos das relações de poder também podem reconfigurar esses discursos.

Lugar de fala está intimamente relacionado ao locus social, que corresponde ao lugar que determinado grupo compartilha, sua localização social dentro de uma estruturada de poder (RIBEIRO, 2017). Pode ser, ainda, considerado como uma localização comum presente nas relações hierárquicas de poder, que criam grupos, possuindo um grau de permanência ao longo do tempo, onde as experiências coletivas ou compartilhadas irão transcender as experiências individuais, ou seja, esses grupos irão possuir histórias compartilhadas com base em seu locus social compartilhado nas relações de poder (COLLINS, 1997).

As experiências individuais são importantes, mas o foco do lugar de fala é a compreensão das condições sociais que irão constituir o grupo ao qual determinado indivíduo faz parte e quais são as suas experiências compartilhadas como grupo (COLLINS, 1997). Com base nessas discussões, quais são os lugares de fala que as mulheres ocupam dentro do campo do empreendedorismo no Brasil?

Sabe-se que a história das mulheres nas ciências foi construída com base em valores e padrões masculinos, o que acabou restringindo, dificultando e também direcionando a participação das mulheres no campo das ciências (PATROCINO et al., 2020). 
A ciência era um território destinado aos homens, visto que foi construída no locus social (COLLINS, 2016) de quem desenvolvia o trabalho produtivo e, assim como qualquer outra profissão, a ciência estava inserida no domínio público, onde as mulheres, destinadas a ocupar o locus social reprodutivo, não tinham espaço (SCHIEBINGER, 2001).

Sendo assim, a inserção das mulheres nas carreiras modernas na ciência foi possível somente após o movimento das mulheres nas décadas de 1870 e 1880, o que acarretou o impulsionamento das mulheres para as universidades (SCHIEBINGER, 2001), movimento este encabeçado pelos grupos feministas que estimularam e exigiram a entrada de mulheres em universidades e centros de pesquisa, bem como no mercado de trabalho, fazendo com que essas mulheres passassem a ocupar esses espaços (LETA et al., 2006).

Entretanto, na academia, os espaços continuam sendo bastidores do poder e do prestígio masculino. Mesmo após discussões, a compreensão e o reconhecimento das barreiras que as mulheres enfrentam para progredir na profissão são aspectos importantes a serem analisados (AISTON; FO, 2021). Identificar, reconhecer e analisar os espaços ocupados por essas mulheres no campo do empreendedorismo visa contribuir com essas discussões, ainda mais, diversas estudiosas feministas enfatizam a natureza sociopolítica da voz e do silêncio como estruturas de poder social que privilegiam algumas vozes em detrimento de outras (AISTON; FO, 2021), sendo assim compreender os lugares de fala das mulheres acadêmicas no campo do empreendedorismo torna-se fundamental para identificar as "vozes" dessas mulheres nos espaços ocupados no campo.

\section{METODOLOGIA}

Liberato e Andrade (2018) demonstram que as relações existentes entre a Ciência e a sociedade são recíprocas - sendo a Ciência capaz de interferir no entendimento e na construção social de determinada sociedade -, isso acaba por influenciar, também, na construção do que é o gênero feminino. É importante reforçar gênero e ciência do ponto de vista ideológico, que irá abranger as dimensões de gênero e padrões de comportamento dentro da comunidade científica, e também em relação a própria Ciência que contribui para desconstruir ou reforçar determinados padrões de comportamento na sociedade (LIBERATO; ANDRADE, 2018).

Com base nisso, e com a finalidade de alcançar o objetivo proposto, a abordagem metodológica utilizada foi quantitativa, por meio de uma bibliometria. A escolha da abordagem quantitativa ocorreu, pois, nesse estudo nosso foco foi direcionado para análise dos aspectos estruturais e institucionais dos lugares de fala. Como tal, considerando que uma das características dos estudos quantitativos é, para além de mensurar, discutir a amplitude da pesquisa, orientados à busca da magnitude e das causas dos fenômenos sociais (SERAPIONI, 2000), essa abordagem possibilitou tanto operacionalizar o escopo do debate institucional do conceito de lugar de fala, quanto articular, nessa perspectiva, as discussões sobre gênero com outras categorias sociais a partir de sua amplitude geográfica e demográfica.

Nesse sentido, a bibliometria, que se caracteriza pela aplicação de métodos matemáticos e também estatísticos em diversos meios de comunicação para quantificar os processos de comunicação escrita (PRITCHARD, 1969), foi operacionalizada a partir das categorias expressas no Quadro 1.

O repositório escolhido para a coleta dos artigos foi o SPELL, sendo os artigos pesquisados a partir do campo de "título do artigo", com a utilização de cinco palavras-chave pré-determinadas intercaladas pelo operador booleano "OU”. Os artigos foram pesquisados entre os anos de 2005-2020, restringidos ao tipo de documento "artigo" e a área do conhecimento em "Administração", os periódicos selecionados foram aqueles classificados como A1, A2 e B1 (Qualis 20132016), ressalta-se que no período analisado não foram publicados artigos em periódicos nacionais A1.

$\mathrm{Na}$ busca inicial dos artigos, que seguiu as etapas descritas acima, foram encontrados 916 artigos, número esse que reflete na amostra total de artigos no período considerado. Após esse levantamento, os artigos foram filtrados com base nos critérios de inclusão e exclusão, sendo considerados para fins de composição da amostra deste estudo apenas 270 artigos. Esse número reflete em $29,47 \%$ do total de artigos encontrados, isso significa que $29,47 \%$ dos artigos 
Quadro 1 O Processo da Pesquisa Bibliométrica

\begin{tabular}{|c|c|}
\hline Repositório & Spell \\
\hline Campo & Título do artigo \\
\hline Termos Pesquisados & "empreendedorismo," "empreendedora", empreendedor", "entrepreneurship"e "entrepreneur" \\
\hline Operador booleano & OU \\
\hline Período de publicação & $2005-2020$ \\
\hline Tipo de documento & Artigo \\
\hline Área do conhecimento & Administração \\
\hline Total de artigos & 916 \\
\hline Qualis (2013-2016) & A1, A2 e B1 (Periódicos Brasileiros) \\
\hline Critério de Inclusão & $\begin{array}{l}\text { Ao menos uma autoria feminina vinculada à uma IES brasileira; } \\
\text { O tema "empreendedorismo" ser central no artigo; }\end{array}$ \\
\hline Critério de Exclusão & $\begin{array}{l}\text { O tema "empreendedorismo" não era central no artigo; } \\
\text { Autoria exclusivamente masculina e/ou estrangeiro(a); } \\
\text { Autoria feminina vinculada à uma IES estrangeira; }\end{array}$ \\
\hline Artigos analisados & 270 \\
\hline Data de corte & $15 / 01 / 2021$ \\
\hline Organizados & Planilha do Excel \\
\hline Analisados & Estatística descritiva \\
\hline Software & RStudio Cloud \\
\hline
\end{tabular}

Fonte: elaborado pelas autoras.

possuíam ao menos uma autoria feminina (podendo ou não ter parcerias com autorias masculinas) e o tema "empreendedorismo" era central no estudo.

Dentre os artigos analisados 116 eram de autoria mista (homens e mulheres) e 154 de autoria exclusivamente feminina. Apesar dos artigos com autorias masculinas e femininas terem sidos considerados para composição da amostra (visto que as autoras também contribuíram na construção dos artigos), para fins de análise, e em consonância com o objetivo do estudo, apenas os dados referentes as autorias ferminas foram considerados para a composição do material empírico.

Em uma planilha do Excel as variáveis relacionadas ao título, nome, sexo das autorias (estabelecido com base nos nomes das autorias), instituição de ensino superior vinculada, ano, periódico, Qualis e tema central foram extraídas para posterior análise, vale lembrar que as informações sobre nome, sexo e instituição de ensino superior de autorias masculinas foram desconsideradas para fins de análise.
As análises estatísticas descritivas foram realizadas a partir do Software RStudio Cloud sendo utilizado em dois momentos: no primeiro, para fazer o agrupamento dos dados advindos da bibliometria, tais como os temas, quantidade de artigos publicados por ano, instituições de ensino vinculadas, dentre outras, fazendo também a sua classificação em ordem decrescente, para identificar quais seriam os principais dados de cada um dos lugares identificados; e no segundo, para fazer a construção dos gráficos.

Essa análise possibilitou a identificação de seis categorias de análise para a compreensão dos lugares de fala, sendo elas: lugares no espaço-tempo; lugares nas publicações; lugares nos periódicos; lugares temáticos; lugares organizacionais; e lugares geográficos. O quadro 2 apresenta os dados utilizados para a construção de cada categoria e também o seu significado:

Uma ressalva deve ser feita em relação aos lugares temáticos no que tange ao agrupamento dos artigos e a criação das categorias temáticas. Para determinar se um tema deveria se tornar uma categoria 
Quadro 2 Composição e significado dos lugares de fala identificados

\begin{tabular}{l|l|l}
\hline \multicolumn{1}{c|}{ Categoria de Análise } & \multicolumn{1}{c|}{ Dados } & \multicolumn{1}{c}{ Significado } \\
\hline Lugares no espaço-tempo & Quantidade de artigos publicados por ano & $\begin{array}{l}\text { Demonstra anualmente a quantidade de artigos } \\
\text { publicados pelas autoras }\end{array}$ \\
\hline Lugares nas publicações & $\begin{array}{l}\text { Quantidade de artigos publicados em revistas A1, A2 } \\
\text { e B1 por ano }\end{array}$ & $\begin{array}{l}\text { Evidencia a qualidade dos artigos publicados com } \\
\text { base no Qualis (2013-2016) agrupados por ano }\end{array}$ \\
\hline Lugares nos periódicos & Periódico onde cada um dos artigos foi publicado & $\begin{array}{l}\text { Apresenta os periódicos nacionais que mais publica- } \\
\text { ram artigos sobre empreendedorismo escritos por } \\
\text { autoras }\end{array}$ \\
\hline Lugares temáticos & $\begin{array}{l}\text { Categorias temáticas identificadas em cada um dos } \\
\text { artigos a partir do tema abordado }\end{array}$ & $\begin{array}{l}\text { Identifica as principais temáticas pesquisadas pelas } \\
\text { autoras }\end{array}$ \\
\hline Lugares organizacionais & $\begin{array}{l}\text { Vinculação institucional das autoras em cada um dos } \\
\text { artigos }\end{array}$ & $\begin{array}{l}\text { Identifica quais são as principais instituições de ensino } \\
\text { superior que foram vinculadas às autorias }\end{array}$ \\
\hline Lugares geográficos & $\begin{array}{l}\text { Localização geográfica das autoras, agrupadas pelas } \\
\text { regiões brasileiras, a partir das instituições de ensino } \\
\text { superior vinculadas em cada uma das autorias dos } \\
\text { artigos }\end{array}$ & $\begin{array}{l}\text { Demonstra como as autoras estão posicionadas } \\
\text { geograficamente com base na região (Sul, Sudeste, } \\
\text { Centro-Oeste, Nordeste e Norte) que as instituições } \\
\text { de ensino superior estão localizadas }\end{array}$ \\
\hline
\end{tabular}

Fonte: elaborado pelas autoras

\section{Quadro 3 Categorias Temáticas}

\begin{tabular}{|c|c|}
\hline \multicolumn{2}{|c|}{ Categoria Temáticas } \\
\hline Alerta Empreendedor & Empreendedorismo Negro \\
\hline Análise de produção científica & Empreendedorismo no Setor Público \\
\hline Aprendizagem Empreendedora & Empreendedorismo Social \\
\hline Atitude empreendedora & Ensino do Empreendedorismo \\
\hline Atividade Empreendedora & Entrevista \\
\hline Características Empreendedoras & Estratégia e Empreendedorismo \\
\hline Competências Empreendedoras & Gênero e Empreendedorismo \\
\hline Comportamento Empreendedor & Incubadoras e Empreendedorismo \\
\hline Educação Empreendedora & Inovação e Empreendedorismo \\
\hline Empreendedorismo & Insucesso Empresarial \\
\hline Empreendedorismo Acadêmico & Intenção Empreendedora \\
\hline Empreendedorismo Coletivo & Liderança Empreendedora \\
\hline Empreendedorismo Cultural & Microempreendedor Individual \\
\hline Empreendedorismo e Políticas Públicas & Motivação empreendedora \\
\hline Empreendedorismo e Sustentabilidade & Orientação Empreendedora \\
\hline Empreendedorismo Feminino & Perfil Empreendedor \\
\hline Empreendedorismo Institucional & Redes e Empreendedorismo \\
\hline Empreendedorismo Internacional & Religião e Empreendedorismo \\
\hline Empreendedorismo Jovem & Universidade Empreendedora \\
\hline
\end{tabular}

Fonte: elaborado pelas autoras 
temática, um critério foi utilizado: era necessário que ao menos dois artigos abordassem aquele tema. Aqueles artigos que possuíam discussões relacionadas ao campo do empreendedorismo como um todo ou que apresentavam discussões sobre um tema muito específico, que não foi discutido em outros artigos, foram agrupados em uma temática geral denominada "Empreendedorismo". O Quadro 2 apresenta as categorias temáticas utilizadas neste estudo:

Dito isso, as próximas seções discutem, a partir dos dados empíricos, os lugares estruturais das mulheres que publicam no campo do empreendedorismo no Brasil, como estão localizadas no campo e também quem são e de onde vêm as principais autoras do campo.

\section{OS LUGARES ESTRUTURAIS}

Para a discussão dos lugares estruturais das autoras no campo do empreendedorismo no Brasil, quatro, das seis categorias de análise, foram articuladas neste debate, sendo elas: lugares no espaço-tempo; lugares nas publicações; lugares nos periódicos; e lugares temáticos. A discussão é iniciada pelo lugar no espaço-tempo, com base nos dados empíricos levantados, organizando os anos em ordem crescente, temos a seguinte quantidade de artigos publicados por ano: 4 - 2005; 8 - 2006; 8 - 2007; 16 - 2008; 10 - 2009; 13 - 2010; 15 - 2011; 21 - 2012; 20 - 2013; 28 - 2014; 28 - 2015; 22 - 2016; 20 - 2017; 18 - 2018; 13 - 2019; e 26 - 2020. Os anos que somaram um maior número de artigos publicados com autorias femininas foram os de 2014 e 2015 - 28 artigos cada.

Gráfico 1 Lugares no espaço-tempo

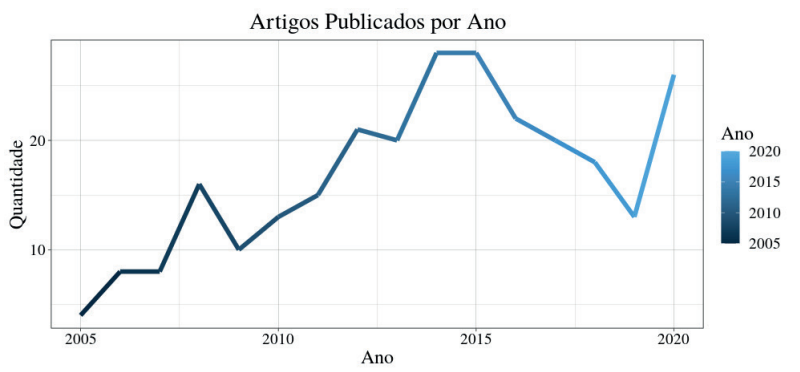

Fonte: elaborado pelas autoras
A partir do ano de 2007 nota-se um crescimento considerável no número de artigos publicados no campo do empreendedorismo, mantendo-se em crescimento até o ano de 2015, com uma maior intensificação entre os anos de 2010 e 2015. Paralelo a esse crescimento, e uma possível contribuição para a elevação do número de artigos, ocorria no Brasil uma mudança na política de ensino superior, impulsionada a partir do ano de 2007 com a criação do Programa de Apoio a Planos de Reestruturação e Expansão das Universidade Federais (Reuni), sendo implementado entre os anos de 2007 e 2011 (SOARES, 2013).

A interiorização e a redistribuição regional foram as principais características do programa, que possuía a finalidade de reduzir a desigualdade na oferta de vagas no ensino superior, novas universidades e unidades encaminharam-se para o interior do país, principalmente para as Regiões Norte e Nordeste (SOARES, 2013).

Entre os anos de 2003 e 2012 houve um incremento nas despesas destinadas às universidades federais, representando uma taxa de crescimento de 151,5\% (SOARES, 2013). Em relação ao Orçamento Previsto e o Valor Empenhado relacionados ao repasse do Governo Federal para as Universidades Federais Brasileiras, entre os anos de 2008 e 2013, houve um crescimento significativo no orçamento destinado às universidades federais, no total de $\mathrm{R} \$ 3,32$ bilhões em 2008 e chegando a R \$ 8,68 bilhões em 2013, o valor empenhado também se aproximou do orçamento previsto, chegando à $\mathrm{R} \$ 3,16$ bilhões em 2008 e R $\$$ 8,66 bilhões em 2013 (OLIVEIRA, 2019, p. 72).

A implementação do Reuni conjuntamente com a intensificação do investimento na educação superior brasileira entre os anos de 2008 e 2013 são fortes indícios da motivação do aumento do número de artigos publicados por mulheres entre os anos de 2007 e 2015. Ressalta-se que entre os anos de 2014 e 2017 houve uma queda constante no repasse feito às universidades federais, onde o valor empenhado não se aproximou do orçamento previsto, além do fato de que a partir do ano de 2015 a verba orçada entrou em decréscimo (OLIVEIRA, 2019).

Concomitante a esse decréscimo, a partir do ano de 2015 até o ano de 2019 houve também uma queda constante no número de artigos publicados pelas mulheres. Porém um fenômeno destoante acontece 
no ano de 2020, em que se tem um aumento expressivo no número de artigos, porém ressalta-se que por ser um fenômeno muito recente e aliado aos efeitos da pandemia da COVID-19, faltam elementos para a construção de análises mais substanciais.

A relação entre o aumento de verbas destinadas à educação e o aumento do número de artigos publicados pelas mulheres possibilita argumentar que os lugares das mulheres também são definidos a partir de políticas estruturais, no sentido de que os lugares das mulheres nas ciências são efeitos das políticas estruturais do Estado. Isso demonstra que a questão de gênero é uma questão estrutural, deve-se pensar esses lugares de fala a partir de políticas públicas que irão trabalhar as especificidades das mulheres.

Outro lugar estrutural é o lugar nas publicações que essas mulheres ocupam. Utilizando o Qualis de 2013-2016 (visto que o referente ao período de 2017-2020 não havia sido publicado oficialmente) desenvolvido pela Capes, restrito neste estudo a periódicos classificados como A1, A2 e B1, foi possível estabelecer uma relação entre quantidade e qualidade dos artigos publicados, demonstrada no gráfico 2 :

Gráfico 2 Lugares nas Publicações

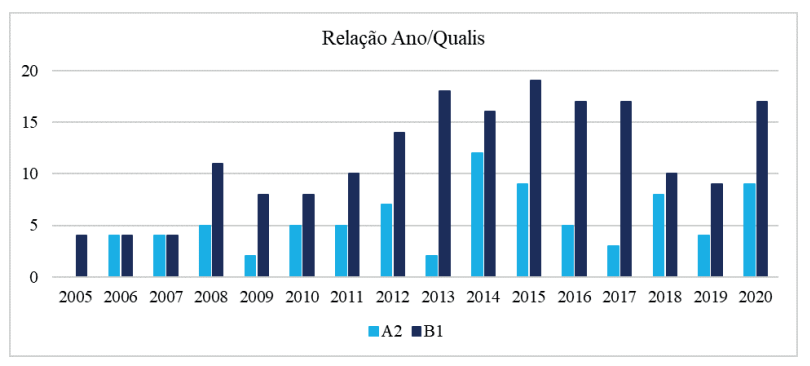

Fonte: elaborado pelas autoras.

Um adendo importante é que no período analisado não houve publicações em periódicos nacionais $\mathrm{A} 1$, dito isso, o ano que contou com o maior número de artigos publicados em revistas A2 foi o de 2014 (12 de 28 artigos) e o ano com o maior número de artigos publicados em periódicos B1 foi o de 2015 (19 de 28 artigos). Quando comparamos o número de publicações em revistas A2 e B1, em nenhum dos anos analisados o número de publicações em revistas A2 superou o número de publicação em revistas B1, isso pode estar relacionado ao número de revistas classificadas como B1 nos dois períodos de análise do Qualis, no de 2010-2012 encontrou-se um número de 276 registros de revista B1, enquanto no de 20132016 esse número sobe para 454, a busca foi feita com base na área de avaliação intitulada de "Administração Pública e de Empresas, Ciências Contábeis e Turismo".

Sabendo dos lugares no espaço-tempo e do lugar nas publicações, os dados apresentaram também os lugares nos periódicos, que demonstram quais foram os periódicos nacionais com o maior número de publicação entre os anos pesquisados. O Gráfico 3 apresenta os principais periódicos que vincularam publicações com autorias femininas entre os anos de 2005 e 2020:

Gráfico 3 Lugares nos Periódicos

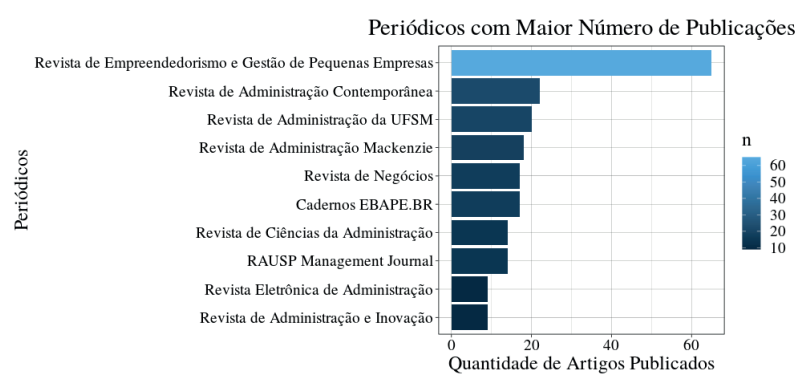

Fonte: elaborado pelas autoras.

Os dados demonstram que os 270 artigos analisados foram publicados em 27 revistas diferentes, sendo a REGEPE (Revista de Empreendedorismo e Gestão de Pequenas Empresas) vinculada à Associação Nacional de Estudos em Empreendedorismo e Gestão de Pequenas Empresas (ANEGEPE), com sua primeira edição publicada em 2012, a que apresentou o maior número de artigos publicados por mulheres, com um total de 65 artigos. A RAC (Revista de Administração Contemporânea) foi o segundo periódico com mais publicações, 22 artigos, enquanto a Revista de Administração da Universidade Federal de Santa Maria (UFSM) soma um total de 20 artigos.

Os lugares temáticos também foram identificados no estudo, demonstrando as principais temáticas estudadas pelas autoras no campo do empreendedorismo. O gráfico 4 apresenta as principais temáticas pesquisadas pelas autoras no campo do empreendedorismo: 
Gráfico 4 Lugares nas temáticas

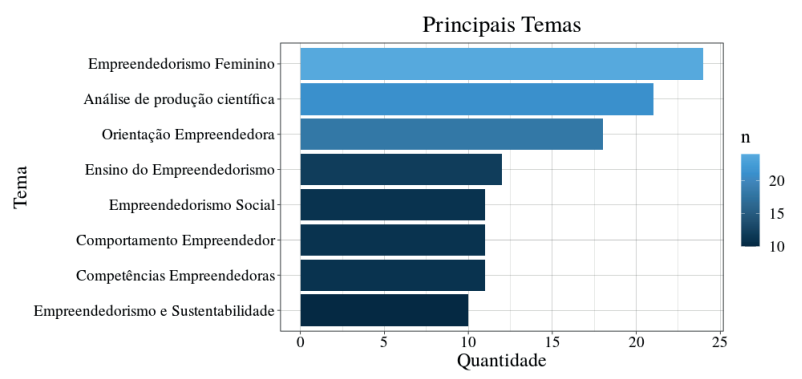

Fonte: elaborado pelas autoras.

A principal temática pesquisada pelas autoras foi "Empreendedorismo Feminino", com 24 publicações, os artigos agrupados nessa temática abordaram a mulher dentro do contexto do empreendedorismo. A temática "Análise da produção científica", somando 21 publicações, apareceu como a segunda temática mais pesquisada, os artigos agrupados nessa temática desenvolveram pesquisas que buscavam fazer a análise da produção científica em diversos temas do empreendedorismo. A terceira temática com maior número de artigos foi a "Orientação Empreendedora" somando 18 artigos, seguida por "Ensino do Empreendedorismo" com 12 artigos.

Uma das evidências que os dados destacam é que um dos lugares das mulheres no campo do empreendedorismo é falando sobre elas, nós, mesmas. "Empreendedorismo Feminino" foi a temática que apresentou maior amplitude de publicações, em partes isso pode estar relacionado a uma escassez histórica de debates sobre o tema, mas também é preciso ter um cuidado para que esse não seja um lugar "autorizado" e exclusivo às mulheres, delimitando suas contribuições apenas nessa temática, ou seja, que ocupem aqueles lugares dedicados apenas para falar sobre elas mesmas, encerrando aí suas participações no campo.

Como demonstrado ao longo do trabalho, no campo científico brasileiro, as mulheres tendem a ocupar lugares que falam sobre o feminino, sendo os outros lugares restritos à sua presença. Os dados do $\mathrm{CNPq}$ demonstram que as mulheres tendem a estar mais presentes em áreas como da Saúde, Ciências Humanas e Linguística, Letras e Artes (MOURÃO; BARROS, 2020). Seria interessante saber, por exemplo, por quem esses textos são lidos e citados, as mulheres falam sobre elas para elas mesmas? A ciência produzida por essas mulheres é direcionada apenas para outras? Mesmo ocupando os espaços acadêmicos as mulheres possuem espaços temáticos "autorizados" para fazerem suas pesquisas? Esses apontamentos são relevantes para uma reflexão dos lugares que estão sendo ocupados por essas mulheres dentro do campo.

A próxima seção apresenta quem são as principais autoras do campo do empreendedorismo no Brasil com base nos dados coletados através da bibliometria, bem como a apresentação dos seus lugares geográficos e também institucionais.

\section{AS PRINCIPAIS AUTORAS DO CAMPO}

Apresentados os lugares estruturais das mulheres no campo do empreendedorismo no Brasil, é hora de identificar e caracterizar as principais autoras do campo, e discutir as outras duas categorias de análise: seus lugares organizacionais e geográficos. Nos 270 artigos analisados foram identificadas 329 autoras, dentre essas, 276 tiveram apenas uma publicação no período analisado (2005-2020) em revistas de Qualis A1, A2 e B1. O Gráfico 5 apresenta as autoras com maior número de publicação a respeito do empreendedorismo no período analisado:

Gráfico 5 Principais autoras

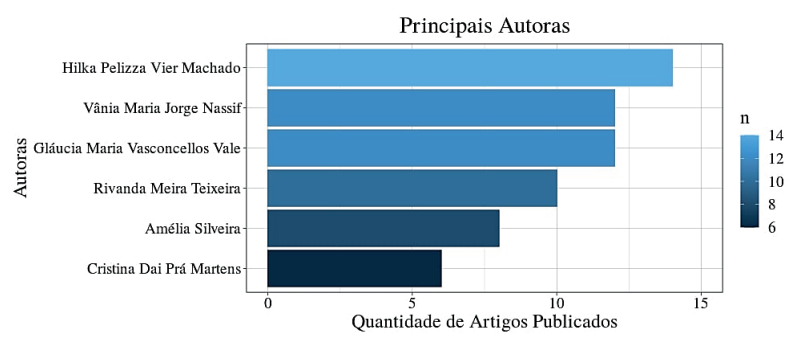

Fonte: elaborado pelas autoras

De acordo com os dados, Hilka Pelizza Vier Machado é a principal autora do campo, possuindo 14 artigos publicados sobre empreendedorismo. As publicações dessa autora estão vinculadas a quatro IES distintas da Região Sul, sendo elas: Centro Universitário de Maringá, Universidade do Oeste de Santa Catarina, Universidade Estadual de Maringá e Universidade Federal de Santa Catarina. As temáticas 
utilizadas em seus artigos foram: Empreendedorismo Feminino (5), Empreendedorismo (2), Redes e Empreendedorismo (2), Alerta Empreendedor (2), Incubadoras e Empreendedorismo (1), Intenção Empreendedora (1) e Inovação e Empreendedorismo (1).

Gláucia Maria Vasconcellos Vale e Vânia Maria Jorge Nassif aparecem em seguida, cada uma com um total de 12 artigos publicados. As publicações dessas autoras foram vinculadas à IES da Região Sudeste: Pontifícia Universidade Católica de Minas Gerais, Universidade Nove de Julho e Universidade Presbiteriana Mackenzie. As temáticas pesquisadas perpassam por: Empreendedorismo (6), Empreendedorismo Feminino (2), Redes e Empreendedorismo (2), Religião e Empreendedorismo (2), Orientação Empreendedora (2), Comportamento Empreendedor (2), Análise da Produção Científica (2), Competências Empreendedoras (2), Motivação Empreendedora (1), Inovação e Empreendedorismo (1), Ensino do Empreendedorismo (1) e Gênero e Empreendedorismo (1).

Rivanda Meira Teixeira aparece como a quarta autora com o maior número de publicações, somando 10 artigos, sendo nove vinculados à uma IES da Região Nordeste - Universidade Federal de Sergipe, e um vinculado à Região Sul - Universidade Federal do Paraná. As temáticas abordadas são: Empreendedorismo Feminino (2), Redes e Empreendedorismo (2), Empreendedorismo Jovem (2), Competências Empreendedoras (1), Empreendedorismo (1), Orientação Empreendedora (1) e Análise da Produção Científica (1).

Amélia Silveira é a quinta autora com maior número de publicações, com um total de 8 artigos, dois deles vinculados à duas IES da Região Sudeste - Universidade de São Paulo e Universidade Nove de Julho, e seis vinculados à três IES da Região Sul - Universidade do Oeste de Santa Catarina, Universidade Federal de Santa Catarina e Universidade Regional de Blumenau. As temáticas de seus artigos foram: Intenção Empreendedora (2), Análise da Produção Científica (2), Empreendedorismo e Sustentabilidade (1), Ensino do Empreendedorismo (1), Redes e Empreendedorismo (1) e Empreendedorismo Feminino (1).

Cristina Dai Prá Martens é a sexta autora com maior número de publicações, com um total de 6 artigos, onde um deles está vinculado à Universidade Federal do Rio Grande do Sul, localizada na Região Sul, e cinco deles estão vinculados à Universidade Nove de Julho, localizada na Região Sudeste. As temáticas de seus artigos perpassam por: Orientação Empreendedora (5) e Análise da Produção Científica (1).

Observa-se que as seis principais pesquisadoras da área representam 22,2\% das publicações, ou seja, dos 270 artigos publicados, 60 foram escritos por uma, ou mais, dessas autoras principais (2 artigos foram escritos em parceria por algumas dessas autoras, por isso o somatório final foi de 60 artigos e não 62 artigos). Em relação ao número de autorias identificadas, 329 nomes, essas seis autoras principais representam apenas $1,8 \%$ desse total, demonstrando a importância dessas autoras para o campo e o quanto são relevantes nos estudos sobre empreendedorismo.

Para caracterizar os espaços ocupados pelas autoras foram identificados os seus lugares institucionais e lugares geográficos. Uma ressalva deve ser feita: durante o período analisado algumas autoras que possuíam mais de uma publicação percorrem por diferentes IES, dessa forma, para captar essa movimentação, optou-se por contabilizar essas autoras individualmente, ou seja, as autoras com mais de uma publicação não foram agrupadas, mas sim consideradas individualmente, assim foram identificadas 329 autorias distintas, porém, o número total de autorias (com repetição dos nomes) nos artigos analisados foi de 451 autorias.

Dito isso, o próximo lugar estrutural apresentado são os lugares organizacionais dessas autoras, esses lugares demonstram suas principais vinculações com organizações no campo científico. O gráfico 6 apresenta as principais universidades vinculadas as autoras em suas produções no campo de estudos sobre empreendedorismo:

\section{Gráfico 6 Lugares Organizacionais}

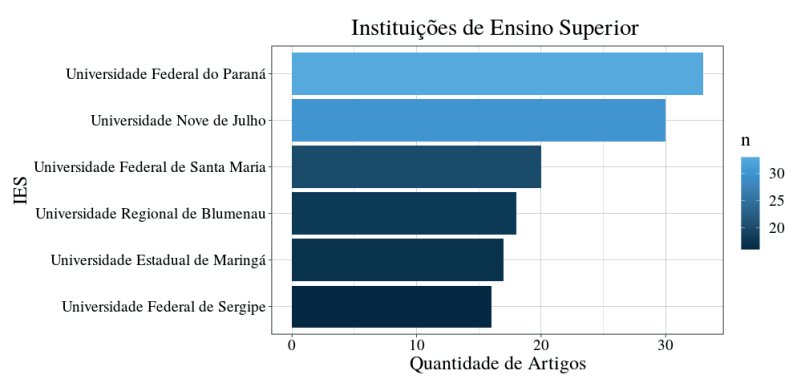

Fonte: elaborado pelas autoras 
De acordo com os dados coletados, as universidades que somam um maior número de vinculação se encontram, em sua maioria, na Região Sul do país. Das seis IES principais, quatro estão localizadas nessa região, sendo elas: UFPR - Universidade Federal do Paraná (33 vinculações), UFSM - Universidade Federal de Santa Maria (20 vinculações), FURB - Universidade Regional de Blumenau (18 vinculações) e UEM - Universidade Estadual do Maringá (17 vinculações). A Universidade Nove de Julho, localizada na Região Sudeste, aparece como a segunda IES com maior número de vinculação (30 autorias vinculadas), enquanto a Universidade Federal de Sergipe, localizada na Região Nordeste, conta com 16 autorias vinculadas, sendo a sexta IES com maior número de vinculação.

Identificados os lugares institucionais, o último lugar estrutural são os lugares geográficos, que demonstram como estão posicionadas, geograficamente, as IES vinculadas às autoras durante o período analisado agrupado pelas Regiões do país. O gráfico 7 apresenta a distribuição geográfica dessas autoras com base nas vinculações institucionais informadas nos artigos:

Gráfico 7 Lugares geográficos

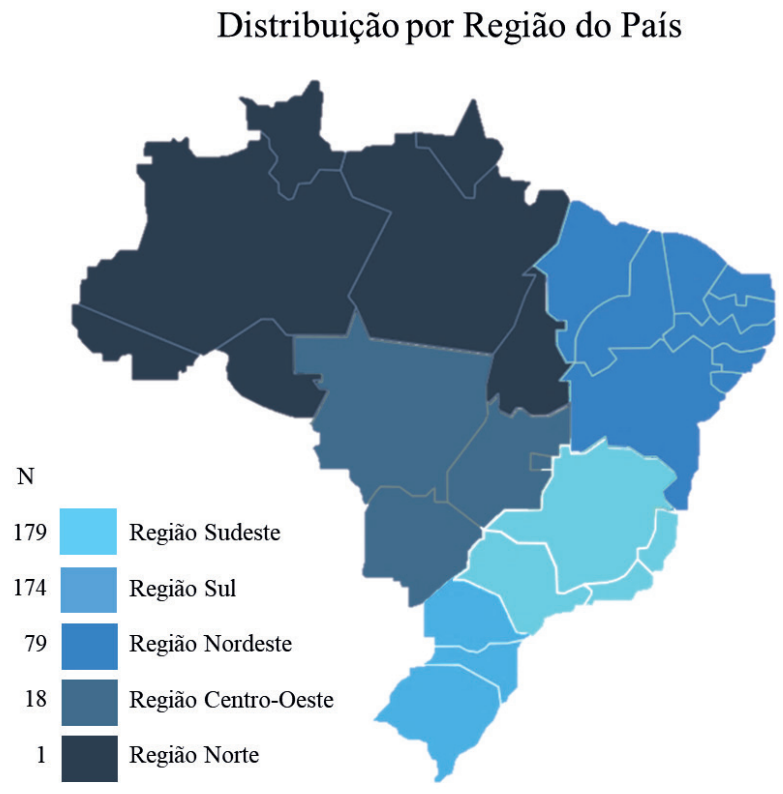

Fonte: elaborado pelas autoras

De acordo com os dados coletados das 451 autorias encontradas: 179 estavam vinculadas à IES localizadas na Região Sudeste do país; 174 vinculadas à IES localizadas na Região Sul; 79 autorias vinculadas à IES da Região Nordeste do país; 18 vinculadas à IES da Região Centro-Oeste; e 1 autoria vinculada à IES da Região Norte.

O Mapa do Ensino Superior no Brasil (2020) demonstra que a região que concentra o maior número de IES é a Região Sudeste (1.123 instituições na modalidade presencial e 185 na modalidade EAD). Essa região contou com o maior número autorias vinculadas às IES no período analisado. Ressalta-se que o ensino do empreendedorismo começou no Brasil pela Fundação Getúlio Vargas em 1980, através de uma disciplina ministrada em um curso de especialização da EAESP - Escola de Administração de Empresas de São Paulo e também através do surgimento de um outro polo do ensino do empreendedorismo organizado pela USP - Universidade de São Paulo (FERNANDES, 2013).

Dessa forma, ressalta-se que a produção científica em empreendedorismo, assim como os lugares das mulheres, tem uma relação direta com a dinâmica estrutural da sociedade. Ou seja, acaba ocorrendo uma reprodução dessa lógica na dinâmica microssocial da área. Essa lógica se configura pela desigualdade social brasileira. Sendo as regiões sudeste e sul as que mais recebem investimentos em termos de constituições de instituições de ensino (ver Gráfico 7), essa lógica se reproduz nas localidades que apresentam maior representatividade no quantitativo de produção de publicações sobre a temática do empreendedorismo no Brasil. Portanto, é uma lógica macrossocial (Estado) que se reproduz na dinâmica da produção científica nas instituições de ensino no país (microssocial).

Ainda segundo o Mapa do Ensino Superior no Brasil (2020), a Região Nordeste apresenta a segunda maior quantidade de IES (567 instituições na modalidade presencial e 132 na modalidade EAD). Essa realidade não refletiu nos dados encontrados em relação à quantidade de autoras vinculadas às IES daquela região, ficando em terceiro lugar nesse ranking, atrás da Região Sul, que contou com 174 autorias vinculadas (essa região possui 413 instituições na modalidade presencial e 142 na modalidade EAD).

A disparidade em relação à essas duas regiões pode ser explicada através dos aspectos socioeconômicos. Mesmo a Região Nordeste contando com o segundo maior número de IES vinculadas, é a 
Região Sul que se destaca no segundo lugar com maior número de autorias vinculadas. De acordo com o IFDM - Índice Firjan de Desenvolvimento Municipal (2018), que acompanha três áreas: 1) Emprego \& Renda, 2) Educação e 3) Saúde, a Região Sul soma um total de $98,8 \%$ dos municípios classificados com desenvolvimento moderado ou alto, enquanto a Região Nordeste tem 50,1\% dos seus municípios classificados com desenvolvimento regular ou baixo. Esse desenvolvimento pode impactar diretamente na capacidade de investimento em pesquisas pelas instituições de ensino, pesquisa e extensão, assim como a capacidade das pesquisadoras. É observado mais uma vez os impactos estruturais na configuração da área de estudos sobre o empreendedorismo.

Outro elemento é que na Região Sul encontra-se uma das pesquisadoras com mais publicações na área. A pesquisadora Hilka Machado, professora aposentada pela UEM - Universidade Estadual do Maringá, atualmente é professora no Centro Universitário UniCesumar e também na Universidade do Oeste de Santa Catarina, concentra um total de 14 artigos publicados na área do empreendedorismo, sendo uma das principais agentes nesse campo. Além da Hilka, outras duas autoras principais do campo também atuaram por um tempo em IES da Região Sul, sendo elas: Rivanda Teixeira na UFPR - Universidade Federal do Paraná (2003-2009/2017-2020) e Amélia Silveira que atuou na FURB - Universidade Regional de Blumenau (1999-2012).

É importante destacar que quando se relaciona o número de autorias vinculadas às IES e a quantidade de IES, a Região Sul apresenta a maior taxa, sendo de 0,31 autoria/por IES. A Região Sudeste apresenta uma proporção de 0,13 autoria/por IES, já a região Nordeste obteve uma proporção de 0,11 autoria/por IES, ou seja, quando comparada às autorias vinculadas/quantidade de IES, mesmo a Região Sudeste apresentando um maior número de vinculação, é a Região Sul que mais se destaca.

Com base nessas afirmações, foram apresentados os lugares estruturais das autoras do campo do empreendedorismo no Brasil, sendo eles: lugares no espaço-tempo, lugares no Qualis, lugares nos periódicos, lugares nas temáticas, principais autoras, lugares geográficos e lugares institucionais. Sendo assim, destaca-se que: os lugares no espaço-tempo refletem uma publicação mais efetiva nos anos de 2014 e 2015; os lugares no Qualis demonstram um maior número de publicação em periódicos A2 no ano de 2014 e B1 no ano de 2015; os lugares nos periódicos apontaram a REGEPE como o principal periódico de veiculação das pesquisas das autoras; os lugares nas temáticas demonstram que o "Empreendedorismo Feminino" é o tema mais abordados nos artigos produzidos por essas autoras; a principal autora do campo é Hilka Machado; os lugares institucionais destacam as IES da Região Sul; e os lugares geográficos indicam a Região Sul como sendo a com maior destaque na vinculação das autorias dos artigos.

\section{CONCLUSÕES}

De acordo com os dados e as discussões apresentadas é possível afirmar que um dos lugares de fala das mulheres no campo do empreendedorismo que mais se destaca é na Região Sul. Isso pode ser observado nos aspectos relacionados às seis principais autoras do campo, nas suas vinculações institucionais e em suas localizações geográficas. Em relação às principais autoras, Hilka Pelizza Vier Machado, considerada a mais relevante no campo, teve todas as suas publicações vinculadas à quatro IES da Região Sul, sendo elas: Centro Universitário de Maringá, Universidade do Oeste de Santa Catarina, Universidade Estadual de Maringá e Universidade Federal de Santa Catarina.

Se a análise partisse de uma vinculação organizacional isolada, a Região Sudeste obteve uma vinculação ligeiramente maior do que a Região Sul, porém quando se analisa os outros aspectos em conjunto, a Região Sul se destaca: é nessa região que está vinculada a principal autora do campo, que demonstra ter uma maior constância nas publicações sobre empreendedorismo; a proporção entre autorias vinculadas/por IES da Região Sul (0,31) é consideravelmente maior do que a Região Sudeste $(0,13)$; das seis principais instituições de ensino superior vinculadas aos artigos quatro estão localizadas na Região Sul; considerando que os aspectos socioeconômicos acabam contribuindo para a capacidade de investimento da região, a Região Sul apresenta o maior índice de desenvolvimento municipal (IFDM) com 98,8\% dos 
seus municípios classificados com o desenvolvimento moderado ou alto (FIRJAN, 2018).

Dito isso, o objetivo deste estudo foi apresentar os lugares de fala, mais especificamente os lugares estruturais, das autoras inseridas no campo do empreendedorismo, aspectos relevantes para a compreensão de como essas mulheres estão posicionadas nesse campo. Uma conclusão apreendida por meio das evidências dos resultados da pesquisa é que existe uma relação direta dos lugares de fala das mulheres pesquisadoras com dinâmicas estruturais da sociedade, a exemplo da dinâmica socioeconômica de onde estão localizadas as organizações das quais enunciam suas pesquisas. Sendo assim, é preciso considerar gênero como uma categoria social estruturante de nossa sociedade sempre em articulação com outras categorias estruturais, conforme destaca a literatura sobre lugar de fala, pois são nessas articulações que os lugares no campo científico se estabelecem.

A centralidade quantitativa das produções em pesquisadoras específicas também é um aspecto importante a ser analisado, pois pode evidenciar a necessidade de fomentar mais trabalhos coletivos nesse campo de forma a não individualizar a produção científica. A contribuição dessas pesquisadoras para o campo é inegável e muito relevante, porém também é necessário fortalecimento coletivo das mulheres que publicam e pesquisam sobre empreendedorismo.

\section{REFERÊNCIAS}

AISTON, S. J.; FO, C. K. The silence/ing of academic women. Gender and Education, v. 33, n. 2, p. 138-155, 2021.

BEAUVOIR, S. DE. O Segundo Sexo: A Experiência Vivida. 2. ed. São Paulo: Difusão Européia do Livro, 1967.

O Segundo Sexo: Fatos e Mitos. 4. ed. São Paulo: Difusão Européia do Livro, 1970.

COLLINS, P. H. Comment on Hekman's Truth and Method Feminist Standpoint Theory Revisited Where's the Power. Signs, v. 22, n. 2, p. 375-381, 1997.
COLLINS, P. H. Aprendendo com a outsider within: A significação sociológica do pensamento feminista negro. Sociedade e Estado, v. 31, n. 1, p. 99-127, 2016.

FERNANDES, R. J. R. Breve histórico do ensino de empreendedorismo no Brasil. Revista GV Novos Negócios, v. 5, n. 5, p. 36-39, 2013.

FIRJAN. IFDM 2018 - Índice Firjan Desenvolvimento Municipal. Publicações FIRJAN: Pesquisas e Estudos Socioeconômicos, 2018.

FOUCAULT, M. A Arqueologia do Saber. 7. ed. Rio de Janeiro: Forense Universitária, 2008.

HAMILTON, E. The discourse of entrepreneurial masculinities (and femininities). Entrepreneurship \& Regional Development, v. 25, n. 1-2, p. 90-99, jan. 2013.

HENRY, C.; FOSS, L.; AHL, H. Gender and entrepreneurship research: A review of methodological approaches. International Small Business Journal: Researching Entrepreneurship, v. 34, n. 3, p. 217-241, 2016.

HOLMQUIST, C.; SUNDIN, E. Is there a place for gender questions in studies on entrepreneurship, or for entrepreneurship questions in gender studies? International Journal of Gender and Entrepreneurship, v. 12, n. 1, p. 89-101, 2020.

JESUS, J. G. DE. Orientações sobre identidade de gênero: conceitos e termos. 2. ed. Brasília: Ed. da Autora, 2012.

LANDSTRÖM, H.; HARIRCHI, G. The social structure of entrepreneurship as a scientific field. Research Policy, v. 47, n. 3, p. 650-662, 2018.

LIBERATO, T. F.; DE ANDRADE, T. H. N. Relações de gênero e inovação: atuação de mulheres nos NITs paulistas. Revista Estudos Feministas, v. 26, n. 2, p. 1-18, 2018. 
LOPES, R. M. A.; LIMA, E. Desafios atuais e caminhos promissores para a pesquisa em empreendedorismo. Revista de Administração de Empresas, v. 59, n. 4, p. 284-292, 2019.

LUKE, C. Women in the Academy: the politics of speech and silence. British Journal of Sociology of Education, v. 15, n. 2, p. 211-230, 1994.

OLIVEIRA, J. A. J. DE. Eficiência dos gastos públicos com ensino superior nas universidades federais brasileiras: uma aplicação da análise envoltória de dados. Dissertação (Mestrado)--Limeira: Universidade Estadual de Campinas, 2019.

PATROCINO, L. B. et al. Mulheres na ciência uma reflexão sobre desigualdade de gênero e raça. Caderno Espaço Feminino, v. 33, n. 1, p. 418-441, 2020.

PEÑALOZA, V.; DIÓGENES, C. G.; SOUSA, S. J. A. Escolha profissional no curso de administração: tendências empreendedoras e gênero. RAM - Revista de Administração Mackenzie, v. 9, n. 8, p. 151-167, 2008.

PRITCHARD, A. Statistical bibliography or bibliometrics? Journal of Documentation, v. 25, n. 4, p. 348-349, 1969

SCHIENBINGER, L. O Feminismo Mudou a Ciência? Bauru: Editora da Universidade do Sagrado Coração, 2001.

SERAPIONI, M. Métodos qualitativos e quantitativos na pesquisa social em saúde: algumas estratégias para a integração. Ciência \& Saúde Coletiva, v. 5, n. 1, p. 187-192, 2000.

REIS, N. DOS; PINHO, R. Gêneros Não-Binários: Identidades, Expressões E Educação. Reflexão e Ação, v. 24 , n. 1, p. 7-25, 2016.

RIBEIRO, D. O que é Lugar de Fala? Belo Horizonte: Letramento, 2017.
SCOTT, J. Gênero: uma categoria útil de análise histórica. Educação \& Realidade, v. 15, n. 2, p. 71-99, 1995.

SEMESP. Mapa do Ensino Superior no Brasil, 2020.

SOARES, L. T. O papel da Rede Federal na expansão e na reestruturação da educação superior pública no Brasil. In: Vinte e um anos de educação superior expansão e democratização. Rio de Janeiro: FLACSO, 2013. p. 5-8. 